\title{
Field-scale validation of an automated soil nitrate extraction and measurement system
}

\author{
Kevin J. Sibley • Tessema Astatkie · Gordon Brewster • \\ Paul C. Struik · John F. Adsett $\cdot$ Kris Pruski
}

Published online: 19 September 2008

(C) The Author(s) 2008. This article is published with open access at Springerlink.com

\begin{abstract}
One of the many gaps that needs to be solved by precision agriculture technologies is the availability of an economic, automated, on-the-go mapping system that can be used to obtain intensive and accurate 'real-time' data on the levels of nitrate nitrogen $\left(\mathrm{NO}_{3}-\mathrm{N}\right)$ in the soil. A soil nitrate mapping system (SNMS) has been developed to provide a way to collect such data. This study was done to provide extensive field-scale validation testing of the system's nitrate extraction and measurement sub-unit (NEMS) in two crop (wheat and carrot) production systems. Field conditions included conventional tillage (CT) versus no tillage (NT), inorganic versus organic fertilizer application, four soil groups and three points in time throughout the season. Detailed data analysis showed that: (i) the level of agreement, as measured by root mean squared error (RMSE), mean absolute error (MAE) and coefficient of efficiency (CE), between NEMS soil $\mathrm{NO}_{3}-\mathrm{N}$ and standard laboratory soil $\mathrm{NO}_{3}-\mathrm{N}$ measurements was excellent; (ii) at the field-scale, there was little practical difference when using either integer or real number data processing; (iii) regression equations can be used to enable field measurements of soil $\mathrm{NO}_{3}-\mathrm{N}$ using the NEMS to be obtained with laboratory accuracy; (iv) future designs of the SNMS's control system can continue to use cheaper integer chip technology for processing the nitrate ionselective electrode $\left(\mathrm{NO}_{3}{ }^{-}\right.$-ISE) readings; and (v) future designs of the SNMS would not
\end{abstract}

K. J. Sibley $(\bowtie) \cdot$ T. Astatkie · J. F. Adsett

Department of Engineering, Nova Scotia Agricultural College, P.O. Box 550, Truro,

NS, Canada B2N 5E3

e-mail: ksibley@nsac.ca

G. Brewster

Department of Environmental Sciences, Nova Scotia Agricultural College, P.O. Box 550,

Truro, NS, Canada B2N 5E3

P. C. Struik

Department of Plant Sciences, Crop and Weed Ecology Group, Wageningen University,

Wageningen, The Netherlands

K. Pruski

Department of Plant and Animal Sciences, Nova Scotia Agricultural College, P.O. Box 550,

Truro, NS, Canada B2N 5E3 
need a soil moisture sensor, ultimately saving on manufacturing costs of a more simple system.

Keywords Soil nitrate measuring - Ion-selective electrode $\cdot$ Precision agriculture

$\begin{array}{ll}\text { Abbreviations } \\ \mathrm{NO}_{3}-\mathrm{N} & \text { Nitrate nitrogen } \\ \mathrm{SNMS} & \text { Soil nitrate mapping system } \\ \mathrm{NEMS} & \text { Nitrate extraction and measurement sub-unit } \\ \mathrm{NO}_{3}-\mathrm{ISE} & \text { Nitrate ion-selective electrode } \\ \mathrm{GPS} & \text { Global positioning system } \\ \mathrm{IN} & \text { Integer number data processing } \\ \mathrm{RN} & \text { Real number data processing } \\ \text { PGW52 } & \text { Pugwash 52 soil group } \\ \text { PGW82 } & \text { Pugwash 82 soil group } \\ \text { DRT22 } & \text { Debert 22 soil group } \\ \text { DRT52 } & \text { Debert 52 soil group } \\ \text { LDM } & \text { Liquid dairy manure } \\ \text { IF } & \text { Inorganic fertilizer } \\ \mathrm{CT} & \text { Conventional tillage } \\ \mathrm{NT} & \text { No tillage } \\ \text { DPM } & \text { Data processing method } \\ \mathrm{IN}+\text { MCC } & \text { Integer number plus moisture content correction data processing } \\ \mathrm{RN}+\mathrm{MCC} & \text { Real number plus moisture content correction data processing } \\ \mathrm{INFits} & \text { Integer number regression fit values } \\ \mathrm{RNFits} & \text { Real number regression fit values }\end{array}$

\section{Introduction}

The profitability and sustainability of modern agriculture are being challenged by economic globalization and environmental concerns. Fertility practices play a major role in both these challenges. Excessive nitrogen fertilizer application may reduce crop profits by potentially increasing fertilizer costs, decreasing crop quality and price, and or depressing yields for crops with a parabolic yield response. Over-application of either inorganic or manure fertilizers can also result in the contamination of water sources and it is also the cause of many of the environmental issues with agricultural production practices (Spalding and Exner 1993; Jemison and Fox 1994; MacDonald 2000; Dinnes et al. 2002).

Precision agriculture offers an exciting opportunity to use highly advanced technology to identify better production practices that not only mitigate associated environmental issues, but also increase the overall sustainability of modern agriculture. The ultimate goal of such technology is to enable farmers to analyze variation more intensively and precisely in field conditions throughout the growing season. For example, environmental and crop response data to make the best site- and time-specific management decisions possible. This capability can offer new production efficiencies to farmers and at the same time offer assurances to the public that agricultural practices are conducted with the minimum possible negative environmental impact. 
One of the many gaps that needs to be solved by precision agriculture technologies is the availability of an economic, automated, on-the-go mapping system that can be used to obtain intensive and accurate 'real-time' data on the levels of nitrate nitrogen $\left(\mathrm{NO}_{3}-\mathrm{N}\right)$ in the soil. The inability to determine soil characteristics rapidly and inexpensively remains one of the biggest limitations of precision agriculture (Adamchuk et al. 2004). If these limitations could be overcome, a positive contribution towards achieving the ultimate goal of precision agriculture would be made.

The soil nitrate mapping system (SNMS) (Fig. 1) could be one such technology; it can obtain the data to analyze soil nitrate variation both spatially and temporally. The SNMS consists of six sub-units (as numbered in Fig. 1): (1) soil sampler, (2) soil metering and conveying, (3) nitrate extraction and measurement, (4) auto-calibration, (5) control and (6) global positioning system (GPS). The system automatically takes a soil sample (0-15-cm depth), mixes it with water, and analyzes it electrochemically for nitrate concentration in real-time $(6 \mathrm{~s})$ with a nitrate ion-selective electrode $\left(\mathrm{NO}_{3}{ }^{-}-\mathrm{ISE}\right)$. Geo-referenced data are recorded simultaneously by GPS at each sampling location to enable a nitrate map to be created for the field. The system can be used to analyze soil samples automatically while on-the-go, or manually while stationary by placing samples by hand into the nitrate extraction and measurement sub-unit (NEMS). It is envisioned that two configurations of the system will eventually be used in practice-a tractor-mounted version (as shown in Fig. 1) and a portable 'suitcase' version (not shown).

From its first prototype (Adsett 1990; Adsett and Zoerb 1991), the SNMS has undergone several developmental iterations. The use of a $\mathrm{NO}_{3}{ }^{-}$-ISE in this type of application has been tested in the laboratory (Thottan et al. 1994; Thottan 1995; Brothers et al. 1997). Development and preliminary field testing of sub-units $1-5$ and their integration into one

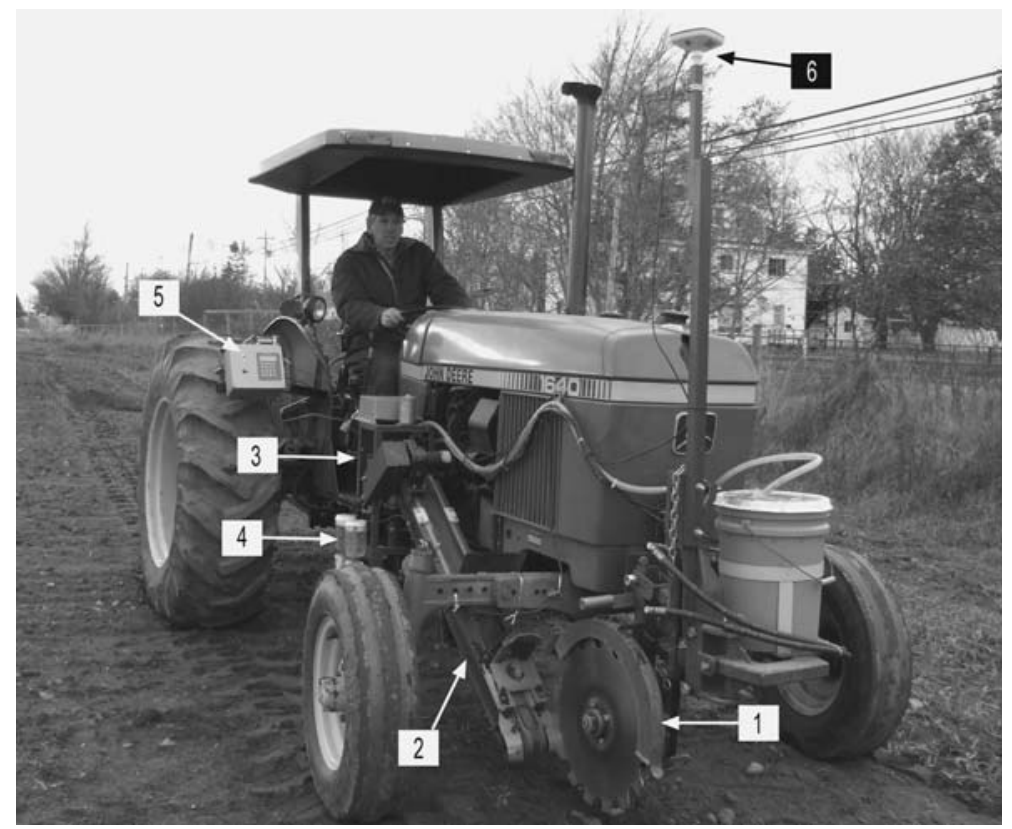

Fig. 1 Soil nitrate mapping system with six sub-units: (1) soil sampler, (2) soil metering and conveying, (3) nitrate extraction and measurement, (4) auto-calibration, (5) control and (6) global positioning system (GPS) 
complete system followed (Thottan 1995; Adsett et al. 1999). In 2001, a new electronics and control system that incorporated the GPS sub-unit was added. The next step in the development of the SNMS was extensive field-scale validation of the NEMS against standard laboratory measurements. In addition, the effect on results obtained by using cheaper integer number (IN) chip technology (as opposed to real number (RN) chip technology) in the control system for processing the $\mathrm{NO}_{3}{ }^{-}$-ISE readings needed to be investigated. It was also of interest to explore whether a soil moisture content sensor was necessary to achieve accurate results in the field.

In this study, field-scale validation testing of the SNMS's NEMS was done with the objectives of determining: (i) the level of agreement between NEMS soil $\mathrm{NO}_{3}-\mathrm{N}$ measurements and standard laboratory measurements for a range of field conditions, (ii) whether IN or $\mathrm{RN}$ data processing of $\mathrm{NO}_{3}{ }^{-}$-ISE readings agreed more closely with standard laboratory measurements, (iii) regression equations to enable field measurements from the NEMS to be given with the accuracy of laboratory measurements and (vi) whether a soil moisture content sensor was necessary to achieve accurate results with the NEMS compared to standard laboratory measurements. The scope of this study was limited to testing in two locally available fields at the same time as other related experiments were being done in two crop production systems (wheat and carrot) of high economic importance to the Atlantic region of Canada in particular, and internationally in general. The field conditions included two crops, two tillage methods, two fertilizer types and four soil groups, as described below.

\section{Materials and methods}

Field sites and experimental designs

During the 2006 season, field experiments were established in two adjacent fields (\#203 and \#207) on the Nova Scotia Agricultural College (NSAC) farm, Truro, Nova Scotia, Canada $\left(45^{\circ} 22^{\prime} \mathrm{N} 63^{\circ} 16^{\prime} \mathrm{W}\right)$ concurrent with other experiments being conducted by the Nova Scotia Water Quality Research Group (NSWQRG). These fields have been used by NSWQRG since 1995 for many bio-environmental, cropping management and water quality studies, and their soils characteristics and cropping histories have been well documented (Webb and Langille 1996; Elmi et al. 2005; Gordon et al. 2005).

The four soil groups in the fields are: (i) Pugwash 52 (PGW52), (ii) Pugwash 82 (PGW82), (iii) Debert 22 (DRT22) and (iv) Debert 52 (DRT52). The PGW52 and PGW82 soil groups have a friable, fine sandy loam textured Ap horizon 15-20 cm thick, underlain by a fine sandy loam textured Bm horizon. Below the Bm horizon is a friable to firm, fine sandy loam textured, platy structured, fragic BCxj horizon. They are moderately welldrained and well-drained, respectively. These soil groups are classified as Orthic HumoFerric Podzol in Canada, which is equivalent to Typic Haplorthod and Orthic Podzol under the FAO and USDA classification systems, respectively. The DRT22 and DRT52 soil groups have a friable, sandy loam textured Ap horizon 25-30 cm thick, underlain by a friable to firm sandy loam textured Bmgj horizon. Below the Bmgj horizon are firm, poorly structured sandy loam to loam textured subsoil horizons that include fragipan (BCxj, BCxjgi) and compact basal till (Cgj). They are both imperfectly drained. These soil groups are classified as Gleyed Sombric Brunisol in Canada, which is equivalent to Cambisol and Dystrochrepts under the FAO and USDA classification systems, respectively. The soil descriptions are according to Webb and Langille (1996). 
Both fields have systematic tile drainage systems (100-mm diameter) installed at $0.8 \mathrm{~m}$ depth with $12 \mathrm{~m}$ spacing between drains. Soil moisture content at the $0-15 \mathrm{~cm}$ depth in the fields during the sampling periods varied between 12.5 and $28.5 \%$ on a wet basis.

Field \#203 comprised soil groups PGW82, DRT22 and DRT52; it was tilled conventionally, seeded with carrot (Daucus carota L.) and had fertility management treatments of liquid dairy manure (LDM) and inorganic fertilizer (IF). Field \#207 comprised soil groups PWG52, DRT22 and DRT52; LDM was applied to the entire field, it was seeded with spring wheat (Triticum aestivum L.) and had tillage management treatments of conventional tillage (CT) and no tillage (NT). Randomized complete block experimental designs were used by NSWQRG in both fields, with soil groups as blocks. Field \#203 had 8 plots (2 fertility treatments $\times 4$ blocks) and Field \#207 had 10 plots (2 tillage treatments $\times 5$ blocks).

\section{Soil sampling and analyses}

Within each field, soil samples were taken at the nodes of a $6.0 \mathrm{~m} \times 7.5 \mathrm{~m}$ grid within the plots to provide soil $\mathrm{NO}_{3}-\mathrm{N}$ data for the $0-15 \mathrm{~cm}$ soil depth. There were 13 sampling locations for each wheat plot and eight for each carrot plot. The grids in each plot were laid out manually in relation to the tile drains so that sampling points were along each drain tile and at mid-points between the drain tiles. Each sampling location was staked to enable repeated sampling and its coordinates were recorded with the GPS. This configuration enabled data to be obtained for this study simultaneously with two other related studies (not reported here) investigating the relationships between soil $\mathrm{NO}_{3}-\mathrm{N}$ and drain water quality, and the spatial and temporal variation of soil $\mathrm{NO}_{3}-\mathrm{N}$.

Soil samples were taken as follows: (i) just before planting and fertilizing (3 May for wheat, 4 May for carrot), (ii) approximately 3 weeks after fertilizing (30 May for wheat, 20 June for carrot) and (iii) after the crop harvest (7 November for both wheat and carrot). Samples were taken manually by coring with a standard $19 \mathrm{~mm}$ diameter tubular soil sampling tool to a depth of $15 \mathrm{~cm}$. Four cores were taken at each location, placed in a plastic bag and mixed to give a bulked sample. All samples were taken within a radius of $0.3 \mathrm{~m}$ of the sampling location and were kept in Styrofoam coolers while in the field. After sampling was completed, they were taken to the laboratory and refrigerated $\left(4^{\circ} \mathrm{C}\right)$ until processing could be completed (6-38 days). A total of 582 soil samples was collected and analyzed for this study.

Standard laboratory analysis for $\mathrm{NO}_{3}-\mathrm{N}$ content of the samples was done in the NSAC's Soils Analysis Laboratory using inorganic $\mathrm{N}$ extraction procedures, according to the methods of Voroney et al. (1993). Moist sub-samples of $\pm 20 \mathrm{~g}$ each were combined with $100 \mathrm{ml}(1: 5$ soil/extractant ratio) of $2 \mathrm{M} \mathrm{KCl}$ and shaken for $60 \mathrm{~min}$ at $170 \mathrm{cps}$. After shaking, all samples were allowed to settle for $15 \mathrm{~min}$, and then filtered through Whatman \#42 filter paper into 20-ml HDPE scintillation vials. The vials were placed immediately into a freezer $\left(-16^{\circ} \mathrm{C}\right)$ until $\mathrm{NO}_{3}-\mathrm{N}$ quantification could be completed (12-36 days). Samples were subsequently thawed, and $\mathrm{NO}_{3}-\mathrm{N}$ was quantified colorimetrically using a Lachat flow injection autoanalyzer (FIA) (Lachat Quickchem, Milwaukee, WI), according to the method of Keeney and Nelson (1982). Moist sub-samples of 10-15 g each were also weighed out at the time of extraction, and the moisture content of each sample was quantified gravimetrically using the standard oven-dry method.

The SNMS analysis of the samples for $\mathrm{NO}_{3}-\mathrm{N}$ content was done using only its NEMS in order to isolate the performance of this sub-unit from that of the soil sampling sub-unit. Calibration of the ion-selective electrode (ISE) was performed using standards prepared 
Table 1 Quality control measures for NEMS analyses

\begin{tabular}{ll}
\hline Control measure & Action \\
\hline $\begin{array}{l}\text { Sample placement timing } \\
\text { Sample consistency }\end{array}$ & $\begin{array}{l}\text { Sample placed into chamber as belt pocket rounded conveyor tail-end roller } \\
\text { Hand-granulated in plastic bag prior to weighing. Weighing } \pm 0.1 \mathrm{~g}\end{array}$ \\
$\begin{array}{l}\text { Electrode calibration } \\
\text { Calibration standards }\end{array}$ & $\begin{array}{l}\text { Electrode calibrations were } 59 \pm 2 \mathrm{mV} / \mathrm{dec} \text { ade } \\
\text { Nanually prepared standards were checked against Orion ionplus certified }\end{array}$ \\
$\begin{array}{l}\text { Temperature } \\
\text { Electrode accuracy and } \\
\text { repeatability }\end{array}$ & $\begin{array}{l}\text { Electrode accuracy and repeatability checked against set of manually prepared } \\
\text { decaded standards }\end{array}$ \\
$\begin{array}{l}\text { Electrode drift } \\
\text { At least one blank and repeat sample measurements were randomly made for } \\
\text { each plot. When drift exceeded } \pm 2 \% \text { electrode sensing module was replaced }\end{array}$ \\
$\begin{array}{l}\text { Electrode response time } \\
\text { Electrode response time in standards compared to stirred soil sample solution }\end{array}$ \\
\hline
\end{tabular}

manually from reagent-grade $\mathrm{KNO}_{3}$ powder and distilled water. Moist sub-samples of $15.1 \mathrm{~g}$ each were weighed out manually and placed in the nitrate extraction and measurement chamber. Extraction and quantification of $\mathrm{NO}_{3}-\mathrm{N}$ was completed automatically in $58.0 \mathrm{ml}$ of vigorously stirred distilled water for $6 \mathrm{~s}$ per sample. The ISE used was a new Orion 9707 ionplus electrode (Thermo Electron Corp., USA). Details of the SNMS's calibration procedures and its functional operation are well documented elsewhere (Thottan et al. 1994; Thottan 1995; Brothers et al. 1997; Adsett et al. 1999). Strict quality control measures (Table 1) were implemented during the analysis to minimize experimental error.

Data processing and statistical analyses

Four data processing methods (DPM) were used for calculating the $\mathrm{NO}_{3}-\mathrm{N}$ content of the soil samples analyzed by the NEMS: (i) integer number (IN); (ii) real number (RN); (iii) integer number plus moisture content correction (IN + MCC); and (iv) real number plus moisture content correction ( $\mathrm{RN}+\mathrm{MCC}$ ). The level of agreement between NEMS measurements and standard laboratory measurements for each DPM was determined by two absolute measures, root mean squared error (RMSE) and mean absolute error (MAE), and one relative measure, coefficient of efficiency $(\mathrm{CE})$.

If NEMS measurements are denoted by $P_{i}$ and standard laboratory measurements are denoted by $O_{i}$, then

RMSE is calculated using

$$
\mathrm{RMSE}=\sqrt{\frac{\sum_{i=1}^{n}\left(O_{i}-P_{i}\right)^{2}}{n}}
$$

MAE is calculated using

$$
\mathrm{MAE}=\frac{\sum_{i=1}^{n}\left|O_{i}-P_{i}\right|}{n}
$$

and CE is calculated using

$$
\mathrm{CE}=1-\frac{\sum_{i=1}^{n}\left(O_{i}-P_{i}\right)^{2}}{\sum_{i=1}^{n}\left(O_{i}-\bar{O}\right)^{2}}
$$


where $\bar{O}$ is the mean of the laboratory measurements and $n$ is the number of data.

Smaller values of RMSE and MAE indicate better performance of the NEMS, but one also needs a reference value of NEMS measurements to judge whether these measures are acceptably small. Perfect agreement gives RMSE and MAE values of zero. The RMSE values are either equal to or larger than the MAE values because they are based on squared deviations, hence are more sensitive to the inflating effect of larger deviations (Astatkie 2006). Both measures were used to assess the presence of extreme differences between laboratory and SNMS measurements. On the other hand, for the unitless relative measure $\mathrm{CE}$, a negative value indicates that estimating the laboratory measurements by the NEMS measurements is worse than estimating them by a typical (average) value, a positive value indicates that estimating the laboratory measurements by the NEMS measurements is better than estimating them by the average, a value of zero indicates that the agreement is as good as estimating all values by the average and a value of one indicates the NEMS measurements are in perfect agreement with the laboratory measurements. A DPM that gives a CE closer to one performs better. Detailed description of these measures and their applications in simulation and forecasting models are available in Astatkie (2006).

For each DPM, simple linear regression models of $Y$ (laboratory value) on $X$ (DPM value) were fitted for the different sampling dates, treatments, soil groups and crops. After verifying the validity of all model assumptions (normality, constant variance and independence), nested linear regression models (Bates and Watts 1988) were fitted and tested to determine if the different groups of data shared a common intercept and slope at the 0.05 level of significance.

After confirming that the different groups shared the same intercept and slope, one final linear regression model was fitted for each DPM using all data combined across sampling dates, treatments, soil groups and crops. These final regression models were fitted to enable field measurements using the NEMS to be given with the same accuracy as those determined in the laboratory.

To determine whether a soil moisture content sensor was necessary to improve the accuracy of results from the NEMS compared to standard laboratory measurements, a comparison of the IN and RN regression equations' fitted values, both with and without moisture content correction, with the laboratory values was made using the performance indicator measures, namely, RMSE, MAE and CE as discussed above.

All raw data calculations were made using Excel (Microsoft Corp., California, USA.; Ver. Prof. Ed. 2003). All measures of agreement, and regression analyses were computed using macros written for and executed by Minitab (Minitab Inc., Pennsylvania, USA; Ver. 15.0).

\section{Results and discussion}

The NEMS data from the first sampling dates for each crop (3 May for carrot and 4 May for wheat) were excluded from the analyses because of inconsistent operation of the NEMS during sample processing. Exclusion of these data did not limit applicability of the NEMS results, however, because the full range of soil $\mathrm{NO}_{3}-\mathrm{N}$ values from the later dates included those from the first dates. The problem with the NEMS operation was rectified prior to processing the remaining samples.

Representative graphs comparing NEMS and laboratory measurements over all the field conditions tested are shown in Fig. 2. These graphs illustrate the admirable performance of 

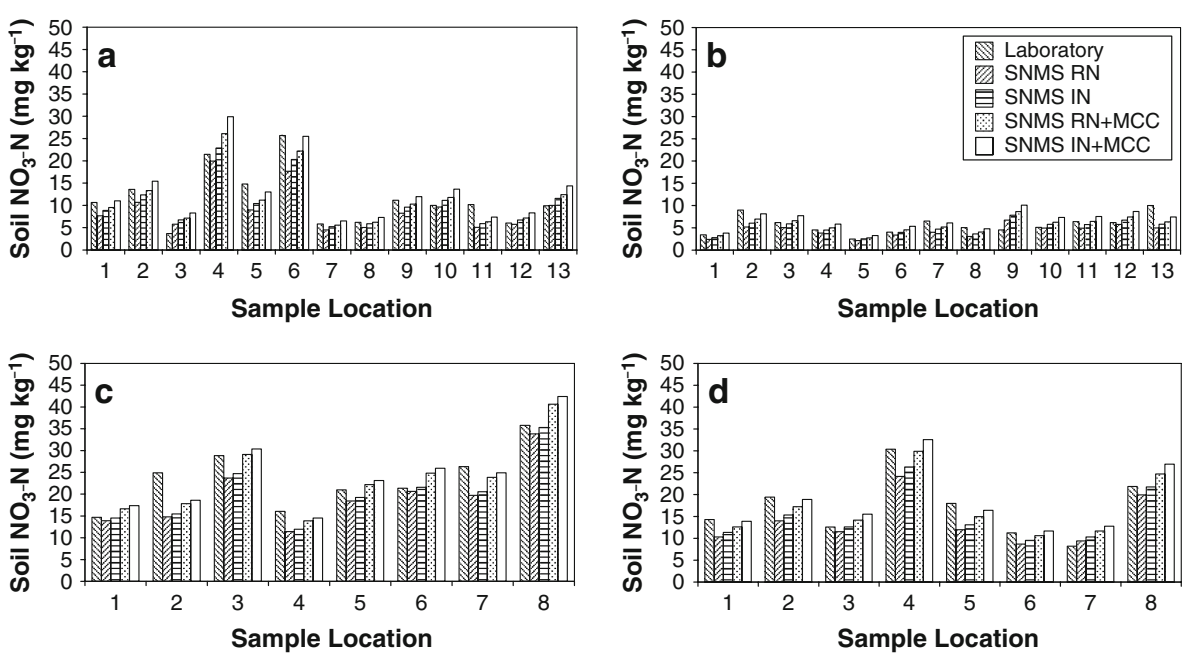

Fig. 2 Comparison of NEMS soil $\mathrm{NO}_{3}-\mathrm{N}$ measurements for each data processing method with laboratory soil $\mathrm{NO}_{3}-\mathrm{N}$ measurements by sample location. (a) Wheat plot 6 (NT, DRT52) on 30 May, (b) wheat plot 8 (CT, PGW52) on 7 November, (c) carrot plot 2 (IF, PGW82) on 20 June and (d) carrot plot 3 (LDM, DRT22) on 7 November

the NEMS on an individual sample basis, regardless of the field condition from which the sample originated. They also indicate the responsiveness of the ISE, as the values are displayed by sampling location ( $x$-axis) in the order of measurement. The electrode appears to respond equally well regardless of whether the $\mathrm{NO}_{3}-\mathrm{N}$ level changes from lower to higher, or higher to lower during a sequence of measurements.

\section{Comparison of NEMS and laboratory measurements}

Table 2 shows that there are no marked differences in the values of the agreement measures for sampling date, treatment, crop or soil group data sets. Therefore, all data sets were combined and the agreement measures were calculated again. For all data combined (first column in Table 2), the RMSE values are between 2.23 and $3.73 \mathrm{mg} \mathrm{kg}^{-1}$, the MAE values are between 1.67 and $2.68 \mathrm{mg} \mathrm{kg}^{-1}$ and the $\mathrm{CE}$ values are between 0.836 and 0.941 . The difference between the RMSE and MAE values is an indication of the presence of some large individual errors. The order of magnitude of the three agreement measures from smallest to largest for comparison with the laboratory values is consistent for the four DPMs, with RN + MCC DPM having the smallest values, followed by IN + MCC, IN, and RN. From a practical perspective, however, all DPMs are close to each other as the maximum difference in MAE values between RN and RN + MCC is only $1.01 \mathrm{mg} \mathrm{kg}^{-1}$ $\left(2.68-1.67 \mathrm{mg} \mathrm{kg}^{-1}\right)$ which is equivalent to $2.32 \mathrm{~kg} \mathrm{ha}^{-1}$. On an absolute basis, the maximum difference between the NEMS and the laboratory values is $2.68 \mathrm{mg} \mathrm{kg}^{-1}$ for the RN DPM, which is equivalent to $6.05 \mathrm{~kg} \mathrm{ha}^{-1}$. It is unlikely that either of these levels of difference would have much consequence on field-scale use of the SNMS.

The same is true for the difference between NEMS measurements with and without moisture content correction. Statistically, moisture content correction of the NEMS measurements are more similar to the laboratory values than those without the correction as shown in Table 2 (CE values: $\mathrm{RN}+\mathrm{MCC}=0.941$ and $\mathrm{IN}+\mathrm{MCC}=0.902$ compared with $\mathrm{RN}=0.836$ and $\mathrm{IN}=0.881$ ). From a practical field perspective, however, the 


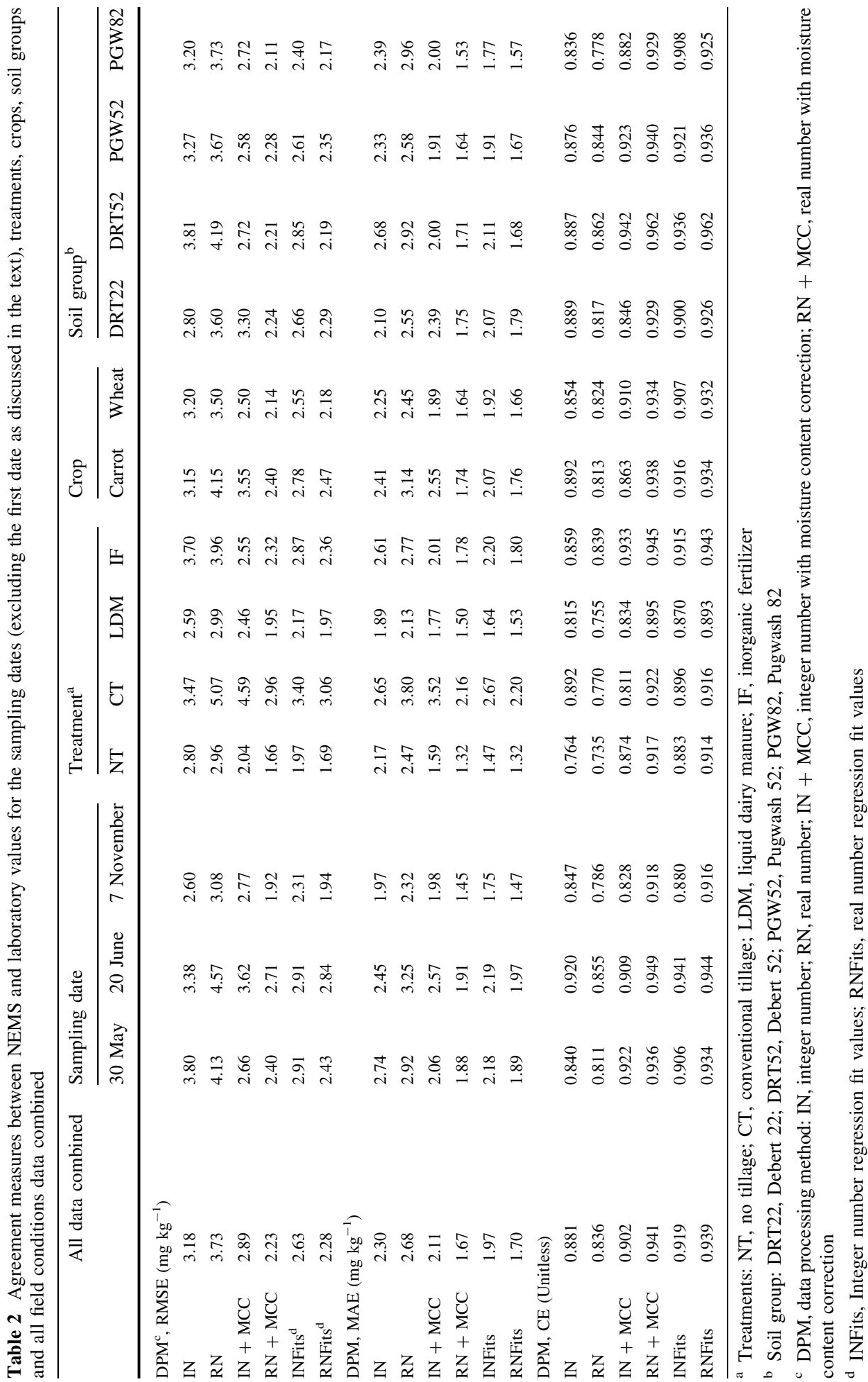


difference is minimal. For the worst case of MAE values between $\mathrm{RN}$ and $\mathrm{RN}+\mathrm{MCC}$, the difference of $1.01 \mathrm{mg} \mathrm{kg}^{-1}\left(2.32 \mathrm{~kg} \mathrm{ha}^{-1}\right)$ would be of little consequence in the field.

Based on these results, we concluded that the level of agreement between $\mathrm{NEMS} \mathrm{NO}_{3}-$ $\mathrm{N}$ measurements and standard laboratory ones for the variety of field conditions tested was excellent. The results also suggest that the NEMS is robust enough to be used in the crops, soil groups, fertility types and tillage conditions tested, as well as at any time throughout the season. Wider testing of the system is required, however, to assess the generality of the findings to other crops, soil textural classes, soil management systems and geographic regions.

Integer number compared with real number data processing

Table 2 shows that the difference in the results between using IN or RN data processing in comparison to standard laboratory measurement is minimal. The three agreement measures are similar when comparing results between the IN and RN DPMs, either alone or with moisture content correction. Without moisture content correction, the RMSE, MAE and $\mathrm{CE}$ values for IN compared with RN are $3.18 \mathrm{mg} \mathrm{kg}^{-1}$ compared with $3.73,2.30 \mathrm{mg} \mathrm{kg}^{-1}$ compared with $2.68 \mathrm{mg} \mathrm{kg}^{-1}$ and 0.881 compared with 0.836 , respectively. With moisture content correction, the RMSE, MAE and CE values for IN compared with RN are $2.89 \mathrm{mg}$ $\mathrm{kg}^{-1}$ compared with $2.23,2.11 \mathrm{mg} \mathrm{kg}^{-1}$ compared with $1.67 \mathrm{mg} \mathrm{kg}^{-1}$ and 0.902 compared with 0.941 , respectively. On an absolute basis, the maximum difference between IN and $\mathrm{RN}$ is $0.44 \mathrm{mg} \mathrm{kg}^{-1}\left(0.98 \mathrm{~kg} \mathrm{ha}^{-1}\right)$. It is unlikely that this level of difference would have much consequence on field-scale use of the SNMS.

Based on these results, we concluded that at the field-scale there was little practical difference in the results when using either the IN or RN data processing method. The implication of this finding is that future designs of the SNMS's control system can continue to use cheaper IN chip technology for processing the $\mathrm{NO}_{3}{ }^{-}$-ISE readings.

Regression analyses

The nested linear regression models had common intercepts and slopes for the different sampling dates (excluding the first dates as discussed above), treatments, soil groups and crops (regressions are not shown here). These results indicate that the NEMS had the same level of performance over all field conditions tested. Therefore, linear regression models for each DPM were fitted for all data combined (Fig. 3). Depending on the data set being modeled, the seven or eight outliers identified during regression with standardized residuals greater than 3.0 were excluded. The final fitted regression equations given below were based on 380 or 381 data points:

For the IN DPM,

$\mathrm{Lab} \mathrm{NO}_{3}-\mathrm{N}=0.727+1.09 \mathrm{NEMS} \mathrm{IN} \mathrm{NO}_{3}-\mathrm{N}\left(R^{2}=0.905, n=381\right)$

For the RN DPM,

$\mathrm{Lab} \mathrm{NO}_{3}-\mathrm{N}=0.131+1.24 \mathrm{NEMS} \mathrm{RN} \mathrm{NO}_{3}-\mathrm{N}\left(R^{2}=0.933, n=381\right)$

For the IN + MCC DPM,

$\mathrm{LabNO}_{3}-\mathrm{N}=0.490+0.89 \mathrm{NEMS} \mathrm{IN}+\mathrm{MCCNO}_{3}-\mathrm{N}\left(R^{2}=0.910, n=380\right)$

For the RN + MCC DPM, 


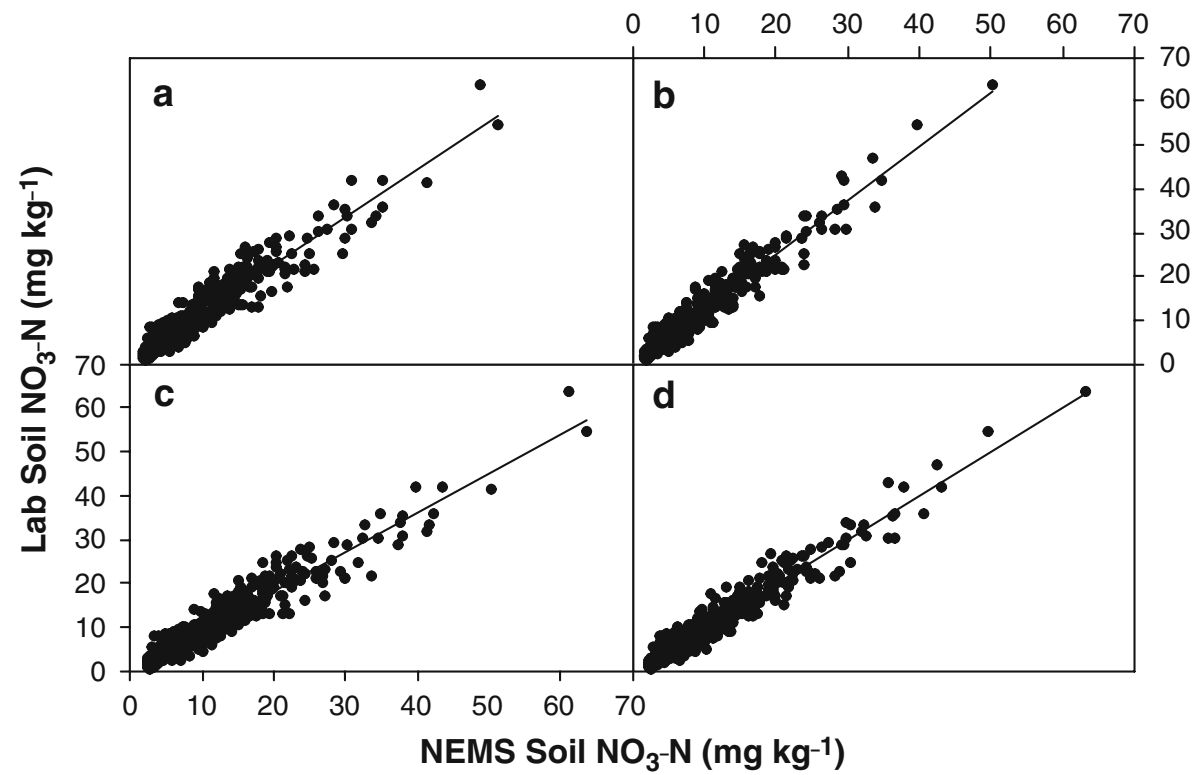

Fig. 3 Relationship between NEMS soil $\mathrm{NO}_{3}-\mathrm{N}$ measurements and laboratory soil $\mathrm{NO}_{3}-\mathrm{N}$ measurements for each data processing method; all field conditions data combined. (a) Integer number data processing, (b) real number data processing, (c) integer number with moisture content correction data processing and (d) real number with moisture content correction data processing

$$
\mathrm{Lab} \mathrm{NO}_{3}-\mathrm{N}=-0.040+1.00 \mathrm{NEMS} \mathrm{RN}+\mathrm{MCC} \mathrm{NO}_{3}-\mathrm{N}\left(R^{2}=0.936, n=381\right)
$$

As for the results of the agreement measures discussed above, the RN + MCC DPM also resulted in the best match to the laboratory measurements $\left(R^{2}=0.936\right.$, slope $\left.=1.00\right)$. However, from a practical perspective all models described the relationship between NEMS measurements and laboratory measurements very well since their $R^{2}$ values were all above $90 \%$.

We concluded that any of the above regression equations that describe the relationship between NEMS measurements and laboratory measurements for the four data processing methods tested could be applied during data processing to enable field measurements of soil $\mathrm{NO}_{3}-\mathrm{N}$ using the NEMS to be given with the same accuracy as laboratory ones.

Soil moisture content sensor

To determine whether a soil moisture content sensor was necessary to achieve results with the NEMS that compare accurately to standard laboratory measurements, a comparison of agreement measures for the IN and RN regression equations' fitted values (INFits, RNFits) with the laboratory values was made (Table 2). For all data combined, the RN fitted values (RNFits CE $=0.939$ ) show a closer agreement with laboratory values than do the IN fitted values (INFits $\mathrm{CE}=0.919$ ). From a practical field perspective, however, either result is just as good ( $2.1 \%$ difference). Table 2 shows that for all data combined, the maximum difference in MAE values between RN + MCC, INFits and RNFits (1.67, 1.97 and 
$1.70 \mathrm{mg} \mathrm{kg}{ }^{-1}$, respectively) of $0.30 \mathrm{mg} \mathrm{kg}^{-1}\left(0.67 \mathrm{~kg} \mathrm{ha}^{-1}\right)$ would have no marked consequence in the field. Therefore, we concluded that future designs of the SNMS would not need a soil moisture sensor, ultimately saving on manufacturing costs and keeping the system design simpler. These results also confirm, as concluded above, that the IN and RN regression equations can be used as predictors of laboratory measurements from NEMS measurements.

\section{Conclusions}

Based on the results of this study, we made the following conclusions. The level of agreement between NEMS soil $\mathrm{NO}_{3}-\mathrm{N}$ measurements and standard laboratory soil $\mathrm{NO}_{3}-\mathrm{N}$ measurements for the variety of field conditions tested was excellent. The results also suggest that the NEMS is robust enough to be used in the crops, soil groups, fertility types, and tillage conditions tested, as well as at any time throughout the season. Wider testing of the system is required, however, to assess the generality of the findings to other crops, soil textural classes, soil management systems and geographic regions. At the field-scale there was little practical difference in the results when using either the IN or RN data processing method. The implication of this finding is that future designs of the SNMS's control system can continue to use cheaper IN chip technology for processing the $\mathrm{NO}_{3}{ }^{-}$-ISE readings. In addition, we concluded that any of the above regression equations that describe the relationship between NEMS measurements and laboratory measurements for the four data processing methods tested could be applied to enable field measurements of soil $\mathrm{NO}_{3}-\mathrm{N}$ using the NEMS to be given with the same accuracy as laboratory ones. Future designs of the SNMS would not need a soil moisture sensor, ultimately saving on manufacturing costs and keeping the system design simpler. Over the range of field conditions tested in this study, accurate predictions of laboratory values can be obtained by using either of the IN or $\mathrm{RN}$ regression equations during data processing calculations of soil $\mathrm{NO}_{3}-\mathrm{N}$ measurements taken with the NEMS.

Acknowledgements Funding for this study, Field Testing and Application of a Soil Nitrate Mapping System, in 2006-2007 was provided by the Nova Scotia Department of Agriculture under the Technology Development Program. A special thank you is extended to Dr. Pat Nelson, Scott Read, Wayne Bhola, Dan Cudmore and Mike Main (research assistants), and Karla Rasmussen, Mila McLean, Katie Atkinson and Kelly Lusby (student research assistants), all with the Engineering Department of the Nova Scotia Agricultural College, for their help with sample collection and processing. The contributions of the Nova Scotia Water Quality Research Group (NSWQRG) and NSAC's Processing Carrot Research Program (PCRP) group are also gratefully acknowledged.

Open Access This article is distributed under the terms of the Creative Commons Attribution Noncommercial License which permits any noncommercial use, distribution, and reproduction in any medium, provided the original author(s) and source are credited.

\section{References}

Adamchuk, V. I., Morgan, M. T., \& Lowenberg-Deboer, J. M. (2004). A model for agro-economic analysis of soil pH mapping. Precision Agriculture, 5, 111-129. doi:10.1023/B:PRAG.0000022357.28154.eb.

Adsett, J. F. (1990). Automated field monitoring of soil nitrate evels. Ph.D. thesis. Saskatoon, Saskatchewan, Canada: University of Saskatchewan). 
Adsett, J. F, Zoerb, G. C. (1991). Automated field monitoring of soil nitrate levels. In Automated Agriculture for the 21st Century (pp. 326-335). ASAE Publication No. 1191. St. Joseph, MI., USA: American Soceity of Agricultural Engineers.

Adsett, J. F., Thotton, J. A., \& Sibley, K. J. (1999). Development of an automated on-the-go soil nitrate monitoring system. Applied Engineering in Agriculture, 15, 351-356.

Astatkie, T. A. (2006). Absolute and relative measures for evaluating the forecasting performance of time series models for daily streamflows. Nordic Hydrology, 37, 205-215. doi:10.2166/nh.2006.008.

Bates, D. M., \& Watts, D. G. (1988). Nonlinear regression analysis and its applications. New York: Wiley.

Brothers, J., Sibley, K. J., Adsett, J. F. (1997). Automated system for soil nitrate analysis. Final Project Report, Agri-focus 2000 program. Truro, Nova Scotia, Canada: Nova Scotia Department of Agriculture \& Marketing.

Dinnes, D. L., Karlen, D. L., Jaynes, D. B., Kaspar, T. C., Hatfield, J. L., Colvin, T. S., et al. (2002). Nitrogen management strategies to reduce nitrate leaching in tile-drained Midwestern soils. Agronomy Journal, 94, 153-171.

Elmi, A., Madani, A., Gordon, R., MacDonald, R., \& Stratton, G. W. (2005). Nitrate nitrogen in the soil profile and drainage water as influenced by manure and mineral fertilizer application in a barley-carrot production system. Water, Air, and Soil pollution, 160, 119-132.

Gordon, R., Elmi, A. A., Madani, A., Hausser, T., Rodd, V., \& Leblanc, P. (2005). Nitrate and pesticide leaving from a processing carrot production system in Nova Scotia. Canadian Journal of Plant Science, 85, 205-211.

Jemison, J. M., Jr., \& Fox, R. H. (1994). Nitrate leaching from nitrogen-fertilized and manured corn measured with zero-tension pan lysimeters. Journal of Environment Quality, 23, 337-343.

Keeney, D. R., \& Nelson, D. W. (1982). Nitrogen: Inorganic forms. In A. K. Page, R. H. Miller \& D. R. Keeney (Eds.), Methods of soil analysis. Part 2. Chemical and microbiological properties (pp. 643709). Madison, WI, USA: American Society of Agronomy.

MacDonald, K. B. (2000). Risk of water contamination by nitrogen. In T. McRae, C. A. S. Smith \& L. J. Gregorich (Eds.), Environmental sustainability of Canadian agriculture: Report of the agri-environmental indicator project (pp. 117-123). Ottawa, ON, Canada: Agriculture and Agri-Food Canada. Publication 2022/E.

Spalding, R. F., \& Exner, M. E. (1993). Occurrence of nitrate in groundwater-A review. Journal of Environment Quality, 22, 392-402.

Thottan, J., Adsett, J. F., Sibley, K. J., \& MacLeod, C. M. (1994). Laboratory evaluation of the ion selective electrode for use in an automated soil nitrate monitoring system. Communications in Soil Science and Plant Analysis, 25, 3025-3034.

Thottan, J. A. (1995). Microcomputer Controlled Soil Nitrate Measurement System. M.A.Sc. thesis. Halifax, Nova Scotia, Canada: Technical University of Nova Scotia.

Voroney, R. P., Winter, J. P., \& Beyaert, R. P. (1993). Soil microbial biomass C and N. In M. R. Carter (Ed.), Soil sampling and methods of analysis (pp. 277-286). Boca Raton, Florida: Lewis Publishers, CRC Press.

Webb, K. T., \& Langille, D. R. (1996). Soils of the Fiddes and Brookside research fields, Colchester County, Nova Scotia-revised. Truro Nova Scotia, Canada: Research Branch, Agriculture and Agri-Food Canada. 